\title{
Criatividade e resiliência na vida de Nise da Silveira
}

\section{Creativity and resilience in the life of Nise da Silveira}

\author{
Maria Antonia de Oliveira* \\ Pontifícia Universidade Católica de Campinas - PUC/Campinas, São J osé do Rio \\ Preto, São Paulo, Brasil
}

\section{Tatiana de Cássia Nakano**}

Pontifícia Universidade Católica de Campinas - PUC/Campinas, Campinas, São Paulo, Brasil

\begin{abstract}
RESUMO
O presente trabalho, síntese de uma dissertação de Mestrado, teve como objetivo analisar a biografia de Nise da Silveira, psiquiatra brasileira eminentemente criativa, que enfrentou situações adversas ao longo de sua trajetória. Buscando por indicadores de criatividade e resiliência em sua história de vida, foi realizada uma análise de diversas fontes documentais, com a intenção de identificar a presença de características criativas e resilientes descritas na literatura científica, a partir de um roteiro de análise desenvolvido pelas pesquisadoras. Os dados obtidos apontam para existência de vários aspectos típicos da pessoa criativa no nível individual (relacionados a aspectos cognitivos, motivacionais, de personalidade, sóciopsicológicos e padrões de vida); no nível de domínio (área específica de destaque, sistemas simbólicos e tipo de prática criativa); no nível de campo (principais mentores, relação com rivais e relação com seguidores) bem como para a presença de características próprias do sujeito resiliente (papel da família e das amizades, autoestima e realização profissional, capacidade de dar sentido à própria vida, resolução de problemas, independência e autonomia, senso de humor e outros) na história de Nise da Silveira. Tais potenciais, criatividade e resiliência, uma vez estimulados, atuaram de maneira decisiva em seu desenvolvimento saudável e eminente.
\end{abstract}

Palavras-chave: criatividade, resiliência psicológica, biografia.

\begin{abstract}
The present paper, synthesis of a Master's thesis, focused on analyzing Nise da Silveira's biography, a Brazilian psychiatrist eminently creative, who went trough adverse situations throughout her trajectory. Looking for creative and resilient evidence in her life story, a study of many documental sources was carried, with the intent of identifying the presence of creative and resilient characteristics described in scientific literature, from an analyses script developed by the researchers. The obtained data points to the existence of many typical aspects of the creative person on the individual level (related to cognitive, motivational, personality, socio-psychological and living standards); domain level (specific area of spotlight, symbolic systems and creative practice type), field level (main mentors, relation with rivals,
\end{abstract}


relation with the followers), as well as to the presence of the resilient person's characteristics (family and friendship roles, self-esteem and professional fulfillment, capacity to give life meaning, problem solving, independence and autonomy, sense of humor and others) at Nise da Silveira's history. Those potentials, creativity and resilience, once stimulated, acted decisively to her healthy and eminent development.

Keywords: creativity, psychological resilience, biography.

\section{I ntrodução}

Atualmente observamos uma situação sem precedentes na história em relação ao acesso a informações, novas descobertas e tecnologia. A humanidade passa por um período de incontáveis problemas sociais, econômicos, políticos e ecológicos.

Vivemos uma emergência planetária, com enormes problemas relacionados entre si: a contaminação e degradação dos ecossistemas, o esgotamento de recursos, o crescimento incontrolado da população mundial, desequilíbrios insustentáveis, conflitos bélicos atrozes e incompreensíveis em nosso grau de civilização, perda da diversidade biológica, linguística e cultural... Tudo isso acrescentado a uma profunda crise econômica global que não parece ser uma crise de crescimento, mas sim uma mudança de sistema (Mallart, 2009, p.29).

Diante desse panorama faz-se presente a necessidade de investimentos voltados à investigação e desenvolvimento de recursos pessoais para fortalecimento e/ou enfrentamento de crises individuais ou grupais, podendo-se destacar aspectos relacionados à criatividade e à resiliência. Essas duas temáticas - criatividade e resiliência - são consideradas mecanismos favoráveis ao desenvolvimento sadio do indivíduo dentro das ideias defendidas pela Psicologia Positiva: movimento que emergiu como uma reação à abordagem psicopatológica, que predominou durante muito tempo na Psicologia, e propõe o estudo dos comportamentos humanos em uma perspectiva focada nas potencialidades e habilidades e não mais em relação aos déficits e sintomas (Taboada, Legal \& Machado, 2006). No leque de tais caracteristicas, a criatividade e a resiliência encontram-se destacadas no presente trabalho.

Uma consulta aos materiais disponíveis na literatura científica mostrou que criatividade (Nakano \& Wechsler, 2007) e resiliência (Oliveira, Reis, Zanelato \& Neme, 2008) são temáticas que, separadamente, vêm recebendo bastante atenção por parte do meio científico. Nota-se, no entanto, uma carência de estudos que investiguem, simultaneamente, os dois temas (Oliveira \& Nakano, 
2011), ainda que o conjunto de tais características venha sendo considerado como recurso para o desenvolvimento pleno do indivíduo. Nesse sentido, a investigação da relação que pode ser estabelecida entre recursos resilientes e características criativas mostra-se de grande valia para a construção de um conhecimento que garanta aos profissionais, das mais diferentes áreas, um embasamento para a elaboração de projetos e programas orientados para a recuperação da saúde, da dignidade e de outros aspectos positivos de milhares de pessoas que sofrem com situações de adversidade. Isso porque, conforme ressalta Lubart (2007), a criatividade, aliada à resiliência, poderia constituir-se em um recurso que permitiria encontrar respostas mais eficazes e soluções mais adaptativas na presença de um ambiente desfavorável. Também, de acordo com Benzoni e Varga (2011), o processo criativo pode ser uma das possibilidades para se sair vitorioso de uma situação traumática.

Definida como a capacidade de algumas pessoas de reagir e recuperar-se diante de determinadas situações traumáticas e impactantes, a resiliência é considerada a possibilidade de realizações favoráveis e positivas, apesar das desvantagens sociais e econômicas que produzem alto risco biológico e social (Uicich, 2006), sendo esta definição adotada no estudo aqui apresentado. Ao longo de décadas, o estudo científico da resiliência vem apresentando uma evolução considerável, marcada não apenas pela elaboração de fundamentos teóricos e princípios metodológicos, mas também pela reunião de um amplo conjunto de evidências que suportam sua consolidação como um construto psicológico (Reppold, Mayer, Almeida \& Hutz, 2012). Nesse sentido, pode ser definido como realização pessoal bemsucedida a situações adversas (Cabral \& Levandowski, 2013). A resiliência envolveria, dessa maneira, não somente o controle sobre a situação, mas também um determinado reforço para que o indivíduo siga lutando por novos e melhores resultados pessoais. Greco, Morelato e Ison (2006) ressaltam que a capacidade de experimentar emoções positivas teria influência sobre as habilidades cognitivas de solução de problemas, a criatividade e sobre o autoconceito, visto que, frente a uma situação-problema, o indivíduo com traços resilientes tenderia a gerar pensamentos alternativos e encontrar soluções criativas.

Já a criatividade poderia ser compreendida como um processo que envolve diferentes etapas: a percepção de lacunas em algum tipo de informação, a identificação de soluções para estas lacunas e a quebra de barreiras. Tais aspectos envolvidos neste processo servem de estímulo para a tietagem e experimentação de novas hipóteses, quebra dos padrões e promoção de mudanças, segundo definição de Torrance e Safter (1999), adotada no presente estudo. 
A relação entre os construtos, abordada por um número pequeno de pesquisadores, mostra que vários autores apresentam um "consenso a respeito de algumas características fixas da resiliência, sendo a criatividade apontada como uma delas" (Yunes, 2006, p.51). Nessa mesma direção, Bragotto (2009) reafirma haver uma relação próxima entre os dois conceitos, ao expressar que "as circunstâncias adversas, ou seja, aquelas contrárias à nossa vontade, que de imediato trazem desconforto e infortúnio, podem ser o mote para um salto inovador" (p.73). Assim, importantes trabalhos podem ser citados. Gregerson (2007), por exemplo, faz um relato significativo, relacionando criatividade e resiliência na sua experiência como testemunha ocular e terapeuta das vítimas do 11 de setembro de 2001, nos Estados Unidos. O autor relata como o uso de recursos criativos (arte terapia, caixa de areia, poesia, meditação e escrita de diário) auxiliou-o a superar seus próprios traumas e também os de outros indivíduos que passaram pelos ataques terroristas.

Outro trabalho encontrado na literatura científica consiste no projeto KusisqaWawa, no Peru, para prevenção dos efeitos negativos dos maus-tratos em criança, "considerado inovador pois trabalha com um enfoque de resiliência que promove a autoestima, a criatividade, 0 humor, autonomia das crianças, além de trabalhar com a família, a comunidade e organizações sociais" (Infante, 2007, p.26). Também Melillo (2007) aponta programas em escolas dos Estados Unidos e da França, nas quais se trabalha a mediação entre pares na resolução de conflitos "para os quais devem ser encontradas, com imaginação e criatividade, soluções não violentas" (p.92). Diferentes relatos também são apontados por Cuestas (2007), na década de 1970, nos chamados anos negros da Argentina, "marcados pela existência de um movimento de resistência à terrível opressão vivida, o qual tinha como cerne a criatividade e a solidariedade" (p.145). Do mesmo modo, destaca-se a experiência, apontada por Estamatti (2007), em um hospital na Argentina, cujas atividades envolviam a realização de oficinas semanais para mulheres no bairro considerado mais vulnerável da cidade, sendo que as estratégias para fortalecer a resiliência enfocaram a esperança de realização de "pequenos grandes sonhos que foram fortalecendo a autoestima, a criatividade, o humor, a independência, a moralidade, a solidariedade, a identidade comunitária" (p.157). De acordo com o autor, os resultados na qualidade de vida foram muito positivos, ocasionando um efeito dominó na comunidade. Vimos, nesses cinco exemplos de enfrentamento de diferentes crises, a palavra criatividade aparecer em todas as situações em que fez-se necessária a busca de soluções para situações adversas.

Uma revisão das características pessoais que favoreceriam ou estariam presentes na criatividade (Greco, Morelato \& Ison, 2006; Guilford, 1967; Romo, 2008; Torrance, 1966; Torrance \& Ball, 1990; 
Torrance \& Safter, 1999; Wallach \& Kogan, 1965; Wechsler, 2008), bem como na resiliência (Bruder, 2005, 2007; Oliveira, Reis, Zanelato \& Neme, 2008; Pinheiro, 2004; Rodriguez, 2007; Sequeira, 2009), mostra que boa parte das características classificadas como pessoais e protetoras encontra-se presente tanto na descrição da pessoa criativa como do indivíduo resiliente. Assim, havendo vários pontos similares entre elas, pode-se citar como exemplos a presença de uma mente aberta e flexível a novas ideias, grande variedade de interesse, capacidade de adaptação e flexibilidade, além do humor, dentre outras.

Ainda que salientada a necessidade de maiores investigações sobre esses dois conceitos, o pequeno número de trabalhos disponíveis sobre a temática reforça a percepção de De La Torre (2005) ao afirmar que "as teorias atuais sobre criatividade apresentam um vazio conceitual em relação às experiências vitais fortes e impactantes" (p.194). Diante dessa constatação, a análise da biografia e condições de vida de pessoas que apresentam essas duas características constitui um importante passo na compreensão de como esses recursos atuam de forma a favorecer o desenvolvimento humano.

Nesse sentido, objetivando analisar a biografia de Nise da Silveira, psiquiatra brasileira eminentemente criativa, que enfrentou situações adversas ao longo de sua trajetória, o presente estudo busca por indicadores de criatividade e resiliência em sua história de vida. Mais especificamente, o trabalho visou: (1) identificar quais características criativas apontadas pela literatura encontram-se presentes na história de vida do sujeito, de forma a apontar aquelas que se encontram bem desenvolvidas; (2) verificar quais características resilientes apontadas pela literatura são identificadas na trajetória de vida do indivíduo pesquisado; (3) apontar, em sua trajetória, uma hipótese acerca de como a criatividade e resiliência encontram-se relacionadas e como, em conjunto, atuaram de forma benéfica para seu desenvolvimento pessoal.

A opção pelo estudo da trajetória desse personagem se deu pela sua importância histórica e social e por seu pioneirismo na história da psicologia, além da constatação de que, em sua vida pessoal e profissional, sempre houve a valorização da expressão criativa e dos aspectos saudáveis do ser humano. Em sua carreira observamos um nível bastante elevado de criatividade ao inovar métodos terapêuticos e promover a humanização no tratamento psiquiátrico com a criação dos ateliês de pintura e modelagem, entre outros. Nise também apresentou diversos traços resilientes ao enfrentar vários tipos de pressões, inclusive sua prisão durante quatorze meses, eventos que serão mais bem explorados ao longo desse trabalho.

\section{Método}


Livros, artigos científicos, entrevistas, documentários, matérias de jornal e de revista e websites foram consultados a fim de que um extenso corpus possibilitasse a coleta de informações sobre a biografia da personalidade escolhida como foco do estudo pudesse ser considerado. Convém salientar, entretanto, um cuidado com o tipo de material selecionado, visando garantir o uso somente daquele que tivesse cientificidade comprovada, a fim de garantir a confiabilidade dos dados. Por isso, optamos por trabalhar somente com revistas, documentários e entrevistas encontradas em meios de comunicação de renome no cenário nacional, livros publicados ou periódicos científicos.

Com a finalidade de direcionar o levantamento dos dados coletados, foi construído um roteiro de análise cujo foco foi a identificação das características relacionadas à criatividade e resiliência na biografia escolhida. O roteiro foi dividido em duas partes: na primeira buscouse analisar a temática da criatividade, tomando-se como referência a definição do modelo de Gardner (1996), que propõe a análise de três sistemas que interagem na criatividade: nível individual, nível de campo e nível de domínio. O primeiro (individual) envolveria quatro aspectos básicos: (1) questões cognitivas, (2) questões motivacionais e de personalidade, (3) questões social-psicológicas e (4) padrões de vida. O segundo nível (domínio), envolve outros três aspectos: (1) natureza dos sistemas simbólicos, (2) tipo de atividade e (3) status de paradigmas. Por fim, o nível do campo envolve a relação com (1) mentores, (2) rivais e (3) seguidores. As definições de cada nível e seus aspectos serão fornecidas por ocasião da apresentação dos resultados e discussão.

Para análise da temática da resiliência também foi elaborado um roteiro usando como referência o documento elaborado por Munist et al. (1998), destacando os atributos: 1) competência social, 2) capacidade de resolução de problemas, 3) autonomia 4) senso de humor e 5) sentido e propósito para de futuro.

\section{Procedimentos}

A pesquisa teve início a partir da coleta de dados sobre a biografia de Nise da Silveira com base nas fontes anteriormente citadas. Depois de reunido o material, uma análise dos registros encontrados foi realizada, de forma a identificar aqueles que pudessem fornecer elementos significativos dentro da temática da criatividade e da resiliência. Os fatos e informações selecionados foram classificados segundo os pontos destacados no roteiro elaborado, procurando identificar episódios indicadores de comportamentos criativos e 
resilientes que amparassem a análise. Posteriormente, buscou-se relacioná-los com a literatura científica.

Deve-se ressaltar, entretanto, que na dissertação da qual se desdobra este artigo, uma análise mais extensa e minuciosa das diversas características, habilidades e contextos presentes na biografia de Nise da Silveira foi realizada. Aqui, apresentamos apenas uma síntese dos dados que foram coletados com a finalidade de explicitar a sua criatividade nos níveis individual (Tabela 1), de domínio (Tabela 2) e de campo (Tabela 3), e também dos principais pontos relacionados aos seus traços resilientes (Tabela 4). Informações mais completas sobre o roteiro elaborado, bem como os critérios utilizados em cada um dos tópicos abordados no mesmo, e as citações das fontes de cada característica e/ou fato mencionado nas três tabelas podem ser encontradas na dissertação da primeira autora, disponível na biblioteca digital da Pontifica Universidade Católica de

Campinas:

http://www.bibliotecadigital. puccampinas.edu.br/tde_busca/arquivo.p hp? codArquivo $=735$.

\section{Resultados e discussão}

\subsection{Aspectos criativos}

A análise inicia-se pela temática da criatividade, organizada de forma a englobar os três sistemas que nela interagem: indivíduo, campo e área (ou domínio), apontados por Gardner (1996), e analisados separadamente. Mais especificamente, a análise do nível individual, composto por cinco aspectos (cognitivos, motivacionais, de personalidade, sócio-psicológicos e padrão de vida), aponta para uma série de pontos importantes, destacados na Tabela 1, de forma a demonstrar que a história de vida de Nise da Silveira é marcada por diversos indicativos de destaque criativo nesse nível. Exemplos e comentários sobre cada um dos aspectos a serem destacados serão apresentados logo após as tabelas. 
Maria Antonia de Oliveira, Tatiana de Cássia Nakano

Criatividade e resiliência na vida de Nise da Silveira

Tabela 1 - Síntese dos registros referentes à criatividade no nível individual

\begin{tabular}{|c|c|}
\hline Aspectos Cognitivos & $\begin{array}{l}\text {-Manifestações de Inteligência Linguística e Social } \\
\text { (interpessoal e intrapessoal) } \\
\text {-Indícios de Altas Habilidades: comportamento prodigioso } \\
\text { precoce }\end{array}$ \\
\hline $\begin{array}{c}\text { Aspectos } \\
\text { Motivacionais }\end{array}$ & $\begin{array}{l}\text { - Mostra motivação intrínseca e focada } \\
\text { - Demonstra grande empenho em suas tarefas } \\
\text { - Não se deixa convencer facilmente } \\
\text {-Demonstra orgulho pelo seu trabalho } \\
\text { - Assume projetos difíceis } \\
\text { - Persiste em suas metas }\end{array}$ \\
\hline $\begin{array}{c}\text { Aspectos de } \\
\text { Personalidade }\end{array}$ & $\begin{array}{l}\text { - Mostra-se tolerante com comportamentos divergentes } \\
\text { - Atua de forma responsável } \\
\text {-Tem disponibilidade para correr riscos } \\
\text { - Projeta imagens positiva para colegas } \\
\text { - É figura de influência }\end{array}$ \\
\hline $\begin{array}{c}\text { Aspectos Sócio- } \\
\text { psicológicos }\end{array}$ & $\begin{array}{l}\text { - Nascida na primeira década sec. XX, período de grandes } \\
\text { mudanças tecnológicas e sociais } \\
\text { - Observação de relações entre contexto vivido na infância e } \\
\text { adolescência e aparecimento de idéias originais/divergente/ } \\
\text { individualizadas. } \\
\text { - Família de classe média alta, atuantes na vida cultural da } \\
\text { cidade } \\
\text { - Primeira reação do contexto sócio cultural pelo seu } \\
\text { trabalho é de rejeição e criação de dificuldades, } \\
\text { posteriormente surgem vários admiradores e seguidores. }\end{array}$ \\
\hline Padrões de vida & $\begin{array}{l}\text {-Apresenta uma perspectiva global } \\
\text { - Usa recursos diversificados } \\
\text { - É flexível no uso de conhecimento } \\
\text {-Aplica conhecimento anterior } \\
\text {-Estilo de pensar e agir: funções predominantes Intuição e } \\
\text { Pensamento }\end{array}$ \\
\hline
\end{tabular}

\section{1) Aspectos cognitivos}

Em relação aos aspectos cognitivos, pode-se destacar, como um dos sinais de altas habilidades, "sua aprovação precoce na Faculdade de Medicina de Salvador, aos 15 anos" (Horta, 2008, p.41). Considera- 
se também indício dessa característica o interesse da jovem Nise por um tipo de leitura mais complexa, "ainda adolescente, deu-se uma paixão: ela conheceu as obras do filósofo Baruch Spinoza" (Horta, 2008, p.42).

Seguindo com os relatos da autora, dentre os tipos de inteligência mais desenvolvidas na personagem, faz-se notar, explicitamente, a inteligência linguística, dado: a) a sua voracidade e paixão pela leitura desde a infância (interesse reforçado por seu pai ao levá-la para visitas ao jornal onde trabalhava); b) por ser grande compradora de livros quando adulta, Nise chegou a ter que comprar um apartamento para abrigar sua biblioteca particular; e c) pelo fato de ter publicado doze livros ao longo de sua carreira. Do mesmo modo, destaca-se sua inteligência pessoal, interpessoal e intrapessoal, "compreendida como a capacidade de lidar com situações pessoais e sociais envolvendo opiniões, sentimentos, motivações ou relações interpessoais" (Almeida, 1994, p.40).

Tais habilidades podem ser percebidas por meio de sua empatia e dedicação sensível e elaborada para com os animais, os doentes mentais e as pessoas em situação de exclusão social, além de sua indignação com a forma de tratamento recebida pelos internos do hospital psiquiátrico onde trabalhava. Em suas próprias palavras: "Eu sou a madrinha dos analistas rebeldes, inadaptados, desajustados, considerados malandros - gosto disso" (Horta, 2008, p.56).

Durante sua atuação profissional, os indícios de inteligência social continuam a se fazer presentes, principalmente pela criação, por Nise da Silveira, de uma nova abordagem não violenta para tratar pacientes internados em hospitais psiquiátricos. Essas vítimas de conflitos psicológicos, esses excluídos socialmente foram beneficiados principalmente pela capacidade que ela demonstrava em entendê-los, respeitá-los, valorizá-los e lutar por eles. Seu trabalho com os internos do hospital psiquiátrico teve um caráter polissêmico, chamando a atenção de diferentes campos do conhecimento. Vê-se em sua história de vida alargada gama de interesses (Morais, 2001), comumente presente nos indivíduos criativos.

\section{2) Aspectos motivacionais}

Sobre tais aspectos, Nise da Silveira também era frequentemente descrita como uma pessoa com forte motivação e persistência. Podese citar, como exemplo disso, uma fala da própria Nise, na qual comenta sobre sua aposentadoria compulsória : “Em 1975, quando me aposentaram - eu não queria - no dia seguinte me apresentei no Museu de Imagens do Inconsciente para trabalhar. 'Sou a mais nova estagiária, voluntária, não quero ganhar nada', eu disse" (Horta, 2008 , p.49). Ela precisava dar continuidade aos seus projetos, mesmo que para isso fosse preciso enfrentar burocracias e 0 
desconforto de pegar diariamente ônibus, aos 70 anos de idade. Ainda segundo palavras da própria Nise,

“há no meu temperamento essa fúria. Quando eu quero uma coisa, eu insisto. Todo o dia, sem falta, eu levantava cedo, pegava o ônibus e ia trabalhar em Engenho de Dentro. Todo dia, todo dia... Nada me tirava daquele caminho. A palavra recuar não faz parte do meu dicionário" (Horta, 2008, p.51).

A importância da motivação para a criatividade é apresentada por Wechsler (2008), ao afirmar que a motivação e a coragem estão intimamente ligadas com a produção criativa, visto que de nada seria útil a presença de altas habilidades ou potenciais naqueles indivíduos que não apresentam motivação para testar nossas ideias ou a coragem de criar. Outros autores, como Candeias (2008), reforçam essa percepção ao afirmar que "para além do mero potencial e ser criativo, um indivíduo precisa estar motivado e orientado por objectivos, quer extrínsecos, quer intrínsecos" (p.49), afirmando ainda que as pessoas criativas habitualmente gostam do que fazem e estão focalizadas no esforço necessário para consegui-lo, muito mais do que nas recompensas (Romo, 2008; Sternberg, 2000). O orgulho pelo seu trabalho também se faz presente nas falas da personagem:

"A verdade é que eu não sou modesta e não quero ser - até porque não sou mesmo! Não tenho modéstia nenhuma, acho meu trabalho de grande importância. Ao mesmo tempo, às vezes, paro, penso. Então acho que fiz pouco. Eu gostaria de ter feito mais... Muito mais!" (Horta, 2008, p.124)

ou ainda

"Tenho orgulho de dizer que transformei o serviço subalterno em serviço de alta categoria. O trabalho que se fazia na Terapia Ocupacional era tudo repetitivo quando fui designada para lá. Eles faziam tudo igual todos os dias. Não existe coisa pior. Criamos oficinas de trabalho criativo..." (Ferreira, 2008, p. 321).

\section{3) Aspectos de personalidade}

Sobre os aspectos de personalidade destacamos, mais marcadamente, sua capacidade de correr risco, ilustrando com o comentário: "Meus primeiros anos de vida foram muito selvagens. Por isso, ainda sou um pouco selvagem... Talvez, muito. Às vezes, sou uma guerreira. Acho que fui mais tempo guerreira do que qualquer outra coisa" (Horta, 2008, p.25). Nesse relato, pode-se 
observar que a disponibilidade para arriscar-se fazia parte da visão de si mesma. No exemplo seguinte, ela ressalta a importância desta atitude e sua relação com a inovação: “Gosto de gente diferente e até perigosa, pois essa gente modifica, transforma. Não há evolução sem riscos" (Horta, 2008, p.284). Gostar de desafios e não ter medo de correr riscos são características tradicionalmente descritas como típicas das pessoas criativas. Wechsler (2008) coloca que "é importante enfatizar que a disponibilidade para aceitar situações de risco envolve certa coragem, que é básica para conseguir a autorrealização criativa" (p.77).

Melo (2001) fala sobre os paradoxos da personalidade de Nise da Silveira da seguinte forma: "A psiquiatria humanitária, carregada de afeto, que se identifica com o sofrimento sem perder a lucidez, encontra sua síntese nesta mulher detentora de opostos: fraca/forte, frágil/firme, tranquila/explosiva, criativa/repetitiva, compreensiva/intransigente" (p.69). Dentre as características de personalidade que merecem destaque, apontamos aspectos da sua capacidade de conviver com diferenças, assim como outras características que também devem ser destacadas, tais como orgulho pelo trabalho realizado, sentido de destino criativo, busca do melhor de si, firmeza na defesa de seus posicionamentos, inconformismo, ousadia e persistência, tolerância à ambiguidade, aspectos diferentes relacionados à analise dos traços de personalidade e da motivação da personagem estudada, valorizados por diversos pesquisadores na área (Csikszentmihalyi, 1998; De La Torre, 2005; Morais, 2001; Wechsler, 2008). $\mathrm{Na}$ prática, formam um amálgama de características interdependentes, embora, nesse caso específico, possamos perceber que a capacidade de assumir projetos difíceis dependeu, em parte, da presença de cada uma delas. Nesse sentido, importante fato ocorreu na ocasião da sua inserção na ala psiquiátrica do hospital. Na época, tratamentos invasivos, tais como eletrochoque, começavam a ser amplamente aplicados nos pacientes, os quais foram imediatamente condenados por ela.

O eletrochoque e os remédios deixavam as pessoas endurecidas, para se acalmarem. E as enfermarias ficavam tranquilas, como os médicos queriam. Ora... isso é tortura!, concluí. Eu não fui torturada nos tempos de cadeia, mas ouvi os gritos de sofrimento de vários companheiros. Seria irônico e absurdo eu ter passado pela prisão e, após solta, torturar os outros. Não faria sentido!... Naquele dia, testemunhei 0 sofrimento do doente, durante a aplicação. Eu disse que não faria aquilo. Os colegas tentavam me convencer sobre as maravilhas daquela engenhoca, mas recusei com firmeza (Horta, 2008, p.88). 


\section{4) Aspectos sócio-psicológicos}

Em relação a esses aspectos, entendemos que o contexto vivido na infância, juventude e início da vida adulta fomentaram em Nise da Silveira um comportamento peculiar, expresso na frase: "A indignação é fundamental para transformação, sem ela não conseguimos mudar quase nada" (Horta, 2008, p.387). Tal posicionamento nos mostra que sua atitude transformadora pressupõe olhar o mundo de forma apurada e crítica. Acreditamos que esta capacidade de indignar-se ou espantar-se diante de situações que outros não percebem está relacionada com um aspecto já mencionado, a capacidade de identificar, definir e redefinir o problema ou tarefa (Lubart, 2007), aliado a uma sensibilidade bem desenvolvida. Podemos ver que toda sua trajetória foi marcada por projetos difíceis, podendo-se elencar alguns: a escolha de uma profissão na qual prevalecia a atuação masculina, sua opção por viver com o companheiro sem legalizar a união (lembrando que isto aconteceu na década de 1920 e 1930), a opção por não ter filhos, o trabalho em hospital psiquiátrico e a recusa aos métodos agressivos de tratamento, a criação das oficinas terapêuticas, a criação do Museu de Imagens do Inconsciente, a criação e manutenção da Casa das Palmeiras, escrita e publicação de mais de 12 livros e a criação do Grupo de Estudo Carl G. Jung. No início da vida adulta, as marcas mais fortes são a perda do pai, as dificuldades para conseguir trabalho, a solidariedade e influência dos amigos no bairro de Santa Teresa, onde residiu logo que chegou ao Rio de Janeiro. "(Nise da Silveira) tem uma história de vida pautada pelas polêmicas e 'edificações' revolucionárias, no campo profissional" (Leal, 1994, p.1). Mesquita (2000), nesse sentido diz: "na década de 1970, outra época de repressão, obscurantismo e arbitrariedade, Nise da Silveira esteve entre os poucos brasileiros que ousaram propor, dentro do serviço público, uma atitude pensante, coerente e, ainda assim sobreviver" (p.62). Ou ainda, nas palavras de Ferreira (2008, p.339) "sempre cobrou com firmeza o descaso e inoperância dos órgãos do poder público no que diz respeito à saúde mental". Em relação ao ambiente familiar, "embora em alguns casos pessoalmente religiosos, eles, de modo geral, demonstravam tolerância em relação ao 'livre pensar' " (p.316), percepção confirmada pela própria Nise da Silveira:

Minha atitude, ao longo da vida, foi resultado do clima que reinava em minha casa, durante a infância. Minha mãe era livre de preconceitos... Era uma pessoa que destoava completamente das mulheres da época. E o meu pai aceitava bem o jeito dela, porque esse também era o jeito dele (Horta, 2008, p.43). 
Segundo Wechsler (2008), o desenvolvimento da criatividade depende bastante do tipo de ambiente que se encontra ao redor, sendo "difícil tentar ser criativo em um ambiente hostil a novas ideias e que reprime o que é diferente" (p.175). Nesse mesmo sentido, Alencar e Fleith (2003) lembram que a existência de condições favoráveis ao desenvolvimento da criatividade estaria também relaciona da aos valores dominantes na família, aos traços de personalidade e interesses aí reforçados e cultivados.

Observamos ainda na trajetória de Nise da Silveira um movimento semelhante ao descrito por Gardner (1996), segundo o qual a criatividade supõe, em um primeiro momento, a ausência do reconhecimento social sendo, só depois de um tempo, a contribuição reconhecida. De acordo com o autor, "poderíamos chegar ao ponto de dizer que uma rejeição inicial é o destino provável de qualquer trabalho verdadeiramente inovador" (p.34). No caso dela, a fase de rejeição à aceitação das importantes contribuições que fez no cenário psiquiátrico brasileiro parece ter sido ainda mais intensa, uma vez que, como coloca Csikszentmihalyi (1998), "pode haver acordo sobre um novo jogo de computador, uma canção de rock ou uma fórmula econômica serem realmente novidade, e portanto criativas; menos fácil é chegar a um acordo sobre a novidade de um ato de compaixão ou de uma visão da natureza humana" (p.48). Nesse sentido, compreendemos que as atuações de Nise da Silveira aconteceram com relação à compaixão e ao respeito à natureza humana dos internos do hospital psiquiátrico e, portanto, com menor probabilidade de ser reconhecida.

A segunda análise acerca do nível de domínio, destaca três pontos, segundo o modelo de Gardner (1996): área específica de destaque, natureza dos sistemas simbólicos e tipo de prática. Uma síntese dos registros referentes à criatividade no nível de domínio é apresentada na Tabela 2. 
Tabela 2 - Síntese dos registros referentes à criatividade no nível de domínio

\begin{tabular}{ll}
\hline Área específica de destaque & $\begin{array}{l}\text { Trabalho reconhecido em diferentes áreas do } \\
\text { conhecimento: saúde, educação, arte, } \\
\text { literatura etc. }\end{array}$ \\
\hline Natureza dos sistemas simbólicos & Psiquiatria e também outros sistemas \\
& simbólicos: artes visuais, teatro, literatura \\
& (mitologia e a escrita técnica/ científica). \\
\hline Tipo de Prática Criativa & Realizações em três contextos: \\
& a) curativo ou da saúde - Oficinas \\
& Terapêuticas e a Casa das Palmeiras; \\
& b) formativo ou educacional - Grupo de \\
& Estudo, Museu de Imagem do Inconsciente e \\
& livros publicados; \\
& c) cultural ou artístico - exposições realizadas, \\
& Museu de Imagem do Inconsciente e \\
& influência nas artes visuais e no teatro. \\
\hline
\end{tabular}

\section{1) Área específica de destaque}

Analisando sua área específica de destaque, vemos que a personagem apresentou, ao longo de sua história, trabalhos reconhecidos em diferentes áreas do conhecimento (saúde, educação, arte, literatura). Tal diversidade vai ao encontro da visão apresentada por Morais (2001), segundo a qual, vários autores associam ao individuo criativo uma forte curiosidade e vastidão de interesses, embora os mesmos possam ser focados, preferencialmente, em um domínio de conhecimento (sendo, nesse caso, a psiquiatria). "Por reconhecimento à sua obra Nise da Silveira tem recebido condecorações, títulos e prêmios nas mais diferentes áreas do conhecimento: saúde, educação, arte, literatura, etc" (Leal, 1994, p.1).

2) Natureza dos sistemas simbólicos

Entendemos que o principal sistema simbólico enfocado pelo seu trabalho era a área da psiquiatria, especificamente a valorização das relações humanas neste domínio. No entanto, conforme comentado anteriormente, cultivou grande interesse por outras áreas, como fica explicitado na fala de Castro e Lima (2007): 
Mantendo-se sempre no campo da psiquiatria, Nise não deixou de buscar parcerias no campo das artes. Demonstrando uma excepcional capacidade de articulação entre campos de Conhecimento, desde o início propôs que o Museu pudesse se tornar um Centro de Estudo aberto não só a psiquiatras, mas também a antropólogos, artistas, críticos de arte interessados pela atividade criadora (p.368).

\section{3) Tipo de prática criativa}

Referindo-se às suas práticas criativas, podemos ver que Nise não só inovou na maneira de olhar, abordar, relacionar-se com os indivíduos internos no hospital psiquiátrico, como também na criação, organização e manutenção de novos tipos de instituições. A Casa das Palmeiras foi uma criação inovadora e pioneira, que visava o oferecimento de um suporte entre a transferência do hospital psiquiátrico e o convívio social dos pacientes (Ferreira, 2008). Também o Museu de Imagens do Inconsciente, que se tornou um centro de estudo e pesquisa, "aberto não só a psiquiatras, mas a antropólogos, artistas, críticos de arte e educadores interessados pelos problemas da psicologia profunda e da atividade criadora" (Mesquita, 2000, p.63).

Nesse sentido, De La Torre (2005) afirma que “(os criativos) são pessoas com enorme energia psíquica a transbordar e que precisam expressá-la, exteriorizá-la de mil maneiras possíveis" (p.29). Por esses exemplos, compreendemos a ampla capacidade de Nise da Silveira, demonstrada nas realizações em três contextos diferentes como algo próprio do perfil da pessoa criativa. Assim, pensamos ser possível responder afirmativamente ao questionamento levantado pelo roteiro elaborado por Gardner (2001): "o trabalho tido como criativo acabou provocando alguma mudança na área?" (p.144/145). Podemos dizer que os relatos encontrados indicam que aconteceram mudanças, não só na área da saúde, a psiquiatria, como também nas artes.

O terceiro e último ponto da análise da criatividade refere-se à investigação de indicadores relacionados ao nível de campo, sintetizados na Tabela 3. 
Tabela 3 - Síntese dos registros referentes à criatividade no nível de campo

\begin{tabular}{ll}
\hline Principais mentores & - O pai, o marido, os professores Antonio Austregésilo e \\
& Ulisses Pernambucano. Também contou com forte \\
& influência de autores como Spinoza e Jung e de vários \\
& amigos artistas e intelectuais. \\
\hline Relações com os rivais & - Enfrentou posições antagônicas com firmeza, distanciou \\
& de alguns colaboradores, buscou parceria da imprensa. \\
\hline Relações com os & -Preocupada em socializar seus conhecimentos e ideais, \\
seguidores & de ter com quem dialogar e continuar aprendendo, \\
& empenhou-se bastante na criação e permanência do \\
& Grupo de Estudos. Geralmente doce e gentil apresentava \\
& também momentos de dureza e rispidez.
\end{tabular}

1) Principais mentores

Nise da Silveira teve alguns mentores próximos e também várias pessoas que exerceram influência em sua vida e criação. Entendemos que a maior influência foi o pai. Sobre ele, ela costumava dizer "Meu pai foi a maior paixão de minha vida" (Horta, 2008, p.44), concordando com os dados de pesquisas na área de criatividade que concluíram que as pessoas eminentes e criativas tiveram, em algum ponto de suas vidas, pessoas que realizaram o papel de mentor (Wechsler, 2008, p.165). Outra figura importante na vida de Nise da Silveira foi o professor Antonio Austregésilo, "considerado o fundador da Neurologia brasileira e um dos precursores da Psicanálise em território brasileiro" (Campos, 2001, p.66). Ainda de acordo com a autora, quando Nise da Silveira foi para o Rio de Janeiro, em 1927, frequentou a "clínica de Neurologia da Faculdade de Medicina, recebendo grande influência de Antonio Austregésilo" (p.356). Foi esse professor que a inscreveu para que prestasse o concurso para psiquiatria (Horta, 2008, p.151).

2) Relações com rivais

Quando aponta a presença dos mentores na vida dos criativos, Gardner (1996) fala também que, "se a pessoa tiver sucesso no trabalho, inevitavelmente encontrará rivais" (p.303). Foi o que aconteceu com Nise da Silveira: em vários momentos do seu percurso profissional enfrentou com firmeza pessoas que não 
entendiam e/ou não aceitavam sua maneira de trabalhar, sua postura e suas ideias.

Com a história de exposição da Seção de Terapêutica Ocupacional no MAM (Museu de Arte Moderna de São Paulo), aumentou ainda mais a raiva que os psiquiatras tinham e têm de mim. Então, eles assistiram ao sucesso do que consideravam garatujas de doentes mentais brilhando em uma exposição badaladíssima. Gente famosa, jornais... Teve até matéria de Sergio Millet! Aquilo tudo foi uma confusão (Horta, 2008, p.235).

\section{3) Relações com seguidores}

Inúmeros foram seus seguidores, constituindo-se em um modelo para os colegas. Outros relatos também indicam esta direção: ela foi uma figura admirada e exerceu grande influência. Vignoli (2000), que conviveu com ela por muitos anos, afirmou: "Ah, querida Nise, quem teve o privilégio de ter te conhecido pessoalmente, vai a vida inteira levar na alma as grandes lições aprendidas contigo... nos marcaram definitivamente; ficamos impregnados com a convivência com a tua fina sensibilidade" (p.1). Inspirados em seus trabalhos, principalmente pela universidade viva, várias pessoas acabaram escrevendo sobre Nise da Silveira ou produziram alguma obra. Frayze-Pereira (2003) cita, como exemplo, a trilogia do cineasta Leon Hirszman chamada "Imagens do Inconsciente" e também artistas e intelectuais como "Graciliano Ramos, Mario Pedrosa, Ferreira Gullar, Frederico Moraes, Jorge de Lima, Sergio Milet, Carlos Drumond de Andrade e muitos outros" (p.2), de forma a confirmar a sua importância.

Após a análise das diversas características que normalmente são utilizadas na literatura para descrever o indivíduo criativo, poder-seia chegar facilmente à conclusão que Nise da Silveira foi, sem dúvida, criativa, após a verificação de indicadores criativos nos três eixos apontados por Gardner (2001). Embora inúmeros fatos tenham sido apontados ao longo dessa análise, convém salientar que, conforme destacado por Morais (2001), alguma precaução deve ser tomada em relação ao valor explicativo, de causa e efeito, das características abordadas. De acordo com a autora,

“nenhuma das características é, por si só, um pré-requisito da criatividade, embora bastante delas apareçam como típicas para essa dimensão acontecer. $O$ fato delas aparecerem associadas a indivíduos criativos não significa mais do que serem correlatos da criatividade, não se podendo inferir uma relação de causa e efeito" (p.79), 
dado o fato de que serem típicas não significa serem necessárias ou suficientes. Por esse motivo, tentou-se evitar que tais características fossem tomadas de forma isolada, através da investigação da biografia da personagem, cuja riqueza poderia trazer clarificações no sentido de se poder avaliar a sua criatividade.

Apresenta-se a seguir o mesmo tipo de análise para decidir-se sobre sua capacidade resiliente, baseando-se, conforme anteriormente explicitado, no modelo de Munist et al. (1998), sintetizados na Tabela 4.

Tabela 4 - Síntese dos registros referentes à resiliência

\begin{tabular}{|c|c|}
\hline $\begin{array}{l}\text { Papel da família e das } \\
\text { amizades }\end{array}$ & $\begin{array}{l}\text { Pais presentes e afetivos. Principalmente o pai, } \\
\text { demonstra muito carinho e apoio. Família aberta ao } \\
\text { cultivo das amizades e acolhimento de pessoas criativas } \\
\text { (artistas). }\end{array}$ \\
\hline $\begin{array}{l}\text { Autoestima e realização } \\
\text { profissional }\end{array}$ & $\begin{array}{l}\text { Apresenta vários sinais de autoestima consistente e } \\
\text { satisfação pelos trabalhos realizados. }\end{array}$ \\
\hline $\begin{array}{l}\text { Capacidade de dar } \\
\text { sentido a própria vida }\end{array}$ & $\begin{array}{l}\text { Em sua trajetória de vida demonstra nitidamente busca } \\
\text { por atividades significativas e coerentes com seus } \\
\text { princípios. } \\
\text { Satisfação com seu trabalho. }\end{array}$ \\
\hline Resolução de problemas & $\begin{array}{l}\text { Em várias situações apresenta comportamento original, } \\
\text { destemido e persistente. } \\
\text { Rebaixamento para a terapia ocupacional } \\
\text { Cegueira }\end{array}$ \\
\hline $\begin{array}{l}\text { Independência } \\
\text { autonomia }\end{array}$ & $\begin{array}{l}\text { Agir com liberdade é um aspecto bastante marcante em } \\
\text { sua vida }\end{array}$ \\
\hline Senso de humor & $\begin{array}{l}\text { Demonstra afinidade por situações inusitadas } \\
\text { engraçadas em diferentes situações. }\end{array}$ \\
\hline Outros fatores & $\begin{array}{l}\text { Apresenta grande valorização pela dignidade humana e fé } \\
\text { em uma dimensão transcendente. }\end{array}$ \\
\hline
\end{tabular}

1) Papel da família e amizades

Como já comentamos anteriormente, pelos relatos da própria Nise da Silveira e de seus biógrafos, observamos que ela teve uma infância cercada de atenção e carinho da família. Esta afirmação vem ao 
encontro do que os pesquisadores de resiliência afirmam em relação à importância dos anos iniciais e da presença de uma figura de apego (Cyrulnik, 2006). De acordo com Melillo (2007), "sem exceção, os estudos identificavam na vida dos resilientes a presença de apoio irrestrito de algum adulto significativo, familiar ou não" (p.11). No caso dela, este apoio veio especialmente do pai.

Ampliando nosso olhar sobre as influências que Nise da Silveira recebeu na infância, observamos que a família estava aberta, cultivando traços de um entorno promotor de resiliência. Diz Ojeda (2007): "pensamos que as chaves explicativas (da resiliência) não estão nas características individuais, mas nas condições sociais, nas relações coletivas e em aspectos culturais e valorativos de cada sociedade" (p.49). Nesse sentido, há em sequência um relato, no qual se torna possível fazer a leitura de que os valores cultivados na família estavam ligados ao acolhimento de pessoas, particularmente os artistas, os divergentes, os excluídos.

2) Autoestima e realização profissional e 3) capacidade de dar sentido à própria vida

Sobre o sentimento de satisfação pessoal e realização profissional, já foram mencionados anteriormente vários exemplos em que ela demonstra sinais positivos a esse respeito. Em seu trabalho, ela encontra sentido para a própria vida: "Quando me perguntam o que mais deu sentido à minha vida, eu respondo: o amor aos loucos" (Horta, 2008, p. 350). Frankl (1987) aponta que "a vida potencialmente tem um sentido em quaisquer circunstâncias, mesmo nas mais miseráveis. E isso, por sua vez, pressupõe a capacidade humana de transformar criativamente os aspectos negativos da vida em algo positivo ou construtivo. Em outras palavras, o que importa é tirar o melhor de cada situação dada" (p.75).

\section{4) Resolução de problemas}

Analisando-se sua capacidade de resolver problemas, um bom exemplo da capacidade de Nise da Silveira encarar uma situação de diferentes maneiras pode ser o episódio relacionado com seu 'rebaixamento' para seção de terapia ocupacional. Ao invés de prender-se na decepção ou sentir-se humilhada, foi flexível, encarouo como um desafio, uma possibilidade de expressar seus princípios e sua força. Entendemos que esta capacidade de encarar uma situação de uma nova maneira vai ao encontro das características próprias de pessoas altamente resilientes. Também pelos relatos, vemos que Nise da Silveira tinha opinião firme para pontos que considerava inegociáveis. Neste exemplo, vimos que, diante de algo para o que não havia alternativa, ela encarava com determinação. Sabia que não 
era fácil encontrar saídas diante de desafios. Disse também: "para navegar contra a corrente, são necessárias algumas qualidades raras: espírito de aventura, coragem, perseverança e, sobretudo, paixão" (Horta, 2008 p.83). Podemos inferir que ela desenvolveu essas qualidades raras e que seu jeito de ser pode ser interpretado como forma resiliente de enfrentar com êxito situações adversas. Este aspecto pode ser relacionado com uma das características apontadas por Melillo e Ojeda (2007), a iniciativa, descrita como "gosto de se exigir e se por à prova em tarefas progressivamente mais exigente" (p.62). Como exemplo, pode-se citar também a fase em que vivenciou a possibilidade de ficar cega. Enfrentou a nova condição, usando uma lupa poderosa para ler e escrever, com a qual exercitava, diariamente, o olho doente. De acordo com Horta (2008),

"ela explicava que via fragmentos de letras e tentava adivinhar o resto, na suposição de que o cérebro se acomodaria. Quando voltou ao oftalmologista, estava lendo com o que lhe restava daquele olho. O médico ficou surpreso. Nunca imaginara que alguém realizasse tamanha façanha" (p.53).

\section{5) Independência e autonomia}

Voltando-se mais especificamente às características de personalidade independência, autonomia e senso de humor, claramente se pode identificar, em sua história, uma enorme capacidade de depender de si mais do que de qualquer outra pessoa. O enfrentamento de pressões permitiu a Nise manter-se firme em situações adversas. Em relação à primeira característica, ela mesma afirmou: "a palavra que mais gosto é liberdade" (Ferreira, 2008, p.318). Sobre sua autonomia, podemos lembrar um episódio anteriormente citado: sua recusa em empregar o tratamento que fazia uso de eletrochoque nos pacientes, motivo pelo qual foi punida com uma transferência, sem que, no entanto, cedesse (Mello, 2001). Outras duas frases, destacadas por Horta (2008), ilustram bem essa autonomia marcante: "Eu não sou junguiana, nem freudiana - nem sicrana... eu sou eu" (p.280) e "A esta altura do campeonato não vou posar de intelectual abestalhada, preocupada com a obra literária" (p.212).

\section{6) Senso de humor}

Por fim, o levantamento da característica senso de humor, destacada por alguns autores como um fator de proteção presente na resiliência (Cyrulnik, 2004; Rodriguez, 2007) mostra que, mesmo ao final da vida, já bem debilitada, essa característica nunca deixou de fazer parte do seu eu: "Na fase em que eu não conseguia ler (depois uma operação Ihe devolveu a visão), havia uma coisa de bom: eu ficava 
ouvindo aqueles homens maravilhosos, lendo para mim, com voz de veludo... Era uma loucura" (Horta, 2008, p.109). Outro relato da mesma autora mostra que "Dra. Nise questionava o peso e a lentidão da máquina burocrática estatal- e, quando preciso, a burlava com bom humor e criatividade" (p.100) ou ainda "o episódio da jovem de família rica, que procurou a psiquiatra, querendo ser analisada - ao perceber que a moça não tinha graves problemas, a dispensou, recomendando o seguinte tratamento: lavar na mão, um tanque de roupa suja por dia" (p.327).

Assim, os pontos indicativos de resiliência destacados na vida de Nise da Silveira parecem apontar para uma personagem e uma história de vida na qual esse fenômeno alcançou grande valor, ao permitir que os episódios negativos fossem superados de forma saudável e impulsionadora. Tal atitude, aliada à criatividade, possibilitaram a ela ampla repercussão de seu trabalho e respeito pelo mesmo.

É com algumas ressalvas que apontamos Nise da Silveira como pessoa criativa e resiliente, pois nosso olhar sobre esses aspectos é sempre determinado pelo contexto em que vivemos e pela nossa subjetividade. Caso Nise da Silveira estivesse viva e tivéssemos a oportunidade de avaliar sua criatividade e resiliência por outros meios (quantitativos, por exemplo), mesmo com os dados biográficos aqui apresentados apontando para a presença forte de tais características, ainda assim, teríamos o cuidado em fazer qualquer afirmação taxativa. Sobre esse ponto, Sternberg (2000) afirma que "não há uma avaliação absolutamente objetiva da inteligência, da criatividade ou do que for. A avaliação é sempre relacionada às normas e às exigências de um grupo específico, em uma época específica e em um lugar específico" (p.170).

Considerando, desse modo, que a criatividade é um conceito complexo e multidimensional, a literatura tem demonstrado que inúmeros são os fatores que podem contribuir e afetar seu desenvolvimento e expressão, de modo a sugerir que a combinação de atributos cognitivos e ambientais poderia convergir na produção de comportamentos criativos (Lubart \& Guignard, 2004). No entanto, indiferente a essa percepção, fez-se notar, historicamente, que a maior parte dos estudos sobre esse construto foi desenvolvida prioritariamente considerando-se a perspectiva individual (Han, 2010), desconsiderando-se, por exemplo, a possibilidade de que o contexto social, os valores, normas e crenças do contexto em que o sujeito pertence pudessem influenciar sua criatividade. Por esse motivo, autores como Cramond (2008) reforçam a necessidade de situar a expressão criativa, tanto em época como cenário, visto que diferentes culturas difeririam em relação aos critérios para sua avaliação.

Por tais motivos, a compreensão dos elementos aqui analisados só faz sentido se consideradas as condições ambientais encontradas por 
Nise da Silveira, em sua época, visto que muitos dos pontos aqui abordados não se fazem mais importantes ou diferenciadores no contexto atual. Pode-se citar, como exemplo, o fato de ser a primeira mulher a frequentar um curso de Medicina, fato comum na atualidade, mas revolucionário em sua história de vida.

\section{Considerações finais}

Ao pretender identificar quais características criativas e resilientes apontadas pela literatura foram identificadas na história de vida do sujeito, bem como traçar uma hipótese acerca de como a criatividade e resiliência encontram-se relacionadas, e como, em conjunto, atuaram de forma benéfica para seu desenvolvimento pessoal, o que visamos, antes de tudo, foi contribuir para o entendimento dos processos criativos e resilientes, de forma a apontar relações entre eles na história de vida da personagem estudada. Em momento algum pretendeu-se esgotar os tópicos analisados em cada um dos fenômenos, mas sim, fornecer exemplos que pudessem embasar a argumentação de preenchimento, ou não, dos critérios apontados como importantes pela literatura. Procurou-se delinear o perfil de uma pessoa com características criativas e resilientes para que tal exemplo de vida possa servir de inspiração, de referência para estudos futuros que busquem investigar a relação entre os dois fenômenos estudados.

Acreditamos que conseguimos traçar o perfil de uma pessoa criativa e resiliente e mostrar como os dois processos, em muitos momentos, estão interligados. Características típicas de um indivíduo criativo coincidem com as de uma pessoa resiliente, podendo citar, como exemplo: a presença de um tutor ou figura de apego nos anos iniciais de desenvolvimento ou da vida profissional; algumas características de personalidade, tais como autoconfiança, humor e vários outros aspectos mencionados ao longo dos nossos relatos.

Entendemos que criatividade está em muitos lugares, dentre eles, na raiz do comportamento resiliente, dado o fato de que esses comportamentos sugerem uma atitude não linear perante uma suposta causa determinista, pressupõem imaginar/inventar/criar outros rumos, ou seja, uma atitude criativa. O inverso também acontece, já que, muitas vezes, ser criativo implica ser resiliente. Criatividade e resiliência frequentemente se apresentam entrelaçadas. É a esta constatação que chegamos: a importância de lidar com a complexidade da vida, a possibilidade de integrar opostos nos processos de construção da criatividade e da resiliência. Assim, ressalta-se a necessidade de que tais fatores sejam cada vez mais valorizados, e estudados empiricamente nas mais diversas áreas que possam investigar as duas temáticas tratadas. 
Sendo a criatividade e resiliência dimensões tão importantes, não deviam ser tratadas só pelo enfoque da psicologia. Acreditamos que a proposta do estudo aqui realizado poderia ser mais rica e consistente se tivéssemos criado oportunidades de discutir as temáticas de forma interdisciplinar com pesquisadores de outras áreas: sociologia, história, antropologia, etc. Poder-se-ia ter melhor explicitado as relações de domínio e campo na vida de Nise da Silveira, considerando-se a possibilidade de fazer uso de recursos que permitissem a complementaridade de visões, de forma que novos estudos biográficos poderiam ser beneficiados por uma leitura interdisciplinar.

Espera-se assim que pesquisadores possam voltar seu olhar para a questão, construindo, em um esforço conjunto, um corpo de conhecimentos sólidos e sistemáticos, capaz de explicar adequadamente a influência de uma série de variáveis (psicossociais, culturais e ambientais) sobre a capacidade de enfrentar a adversidade e sair fortalecido dela.

Considerando que o fenômeno da criatividade, por ser bastante amplo e complexo, assim como a resiliência, permite ao sujeito o máximo aproveitamento dos recursos e oportunidades que se apresentam. Muita coisa destrutiva pode ser feita com criatividade, e também muita coisa boa. Quais seriam então os elementos que podem fornecer condições de decidir qual lado seguir? Como aperfeiçoar a construção de uma sociedade melhor, que reconheça a importância e cuide adequadamente da capacidade de superar obstáculos e do potencial criativo e resiliente humano?

Esperamos que outros trabalhos possam caminhar na busca de respostas a essas indagações. Enfim, desejamos que o estudo aqui desenvolvido possa inspirar um convite: cada indivíduo ser realmente autor de sua vida, fazendo uso da criatividade e resiliência, de forma que, somente após essa mudança ocorrer individualmente, possa ser ampliada para o coletivo, em busca da criação de condições para uma vida melhor para si e para os outros, assim como fez Nise da Silveira.

\section{Referências}

Alencar, E.M.L.S. \& Fleith, D. (2003). Contribuições teóricas recentes ao estudo da criatividade. Psicologia Teoria e Pesquisa, 19(1), 01-08.

Almeida, L.S. (1994). Inteligência: Definição e medida. Aveiro: CIDInE.

Benzoni, S.A.G., \& Varga, C.R.R. (2011). Uma análise de artigos sobre resiliência a partir de uma leitura Kleiniana. Psicologia em estudo, 16(3), 369-378. 
Bragotto, D. (2009). Inovação existencial: entre adversidades e oportunidades criativas. In Z. G. Giglio, S. M. Wechsler, \& D. Bragotto. Da criatividade à inovação (pp.71-83). Campinas: Papirus.

Bruder, M. (2005). El cuento terapéutico como favorecedor de laresiliencia. Una primera aproximación. Psicodebate, 6, 15-28.

Bruder, M. (2007). Holocaustos y resiliencia. Sandando heridas através de la escritura y cuentoterapéutico. Psicodebate, 8, 716.

Cabral, S.A. \& Levandowski, D.C. (2013). Resiliência e psicanálise: aspectos teóricos e possibilidades de investigação. Revista Latinoamericana de Psicopatologia Fundamental, 16(1), 42-55.

Campos, R. H. F. (2001) Dicionário Biográfico da Psicologia no Brasil - Pioneiros. Rio de Janeiro, Imago.

Candeias, A. A. (2008). Criatividade: Perspectiva integrativa sobre conceito e sua avaliação. In M. F. Morais \& S. Bahia (Coords.), Conceito, necessidades e intervenção (pp.41-63). Braga: Psiquilibrios.

Castro, E. D. \& Lima, E.M.F.A. (2007). Resistência, inovação e clínica no pensar e no agir de Nise da Silveira. Interface, 11(22), 365376.

Cramond, B. (2008) Creativity: an international imperative for society and individual. In M.F. Morais \& S. Bahia (Orgs.), Criatividade: conceitos, necessidades e intervenção (pp.13-40). Braga: Psiquilíbrios.

Csikszentmihalyi M. (1998). Creatividad. Barcelona: Paidós.

Cyrulnik, B.(2004). Os Patinhos feios. São Paulo: Martins Fontes.

Cyrulnik, B. (2006). Falar de amor à beira do abismo. São Paulo, Martins Fontes.

Cuestas, A. (2007). A resiliência à opressão. In A. Melillo \& E.N.S. Ojeda (Orgs.), Resiliência, descobrindo as próprias fortalezas (pp.145-149). Porto Alegre: Artmed.

De La Torre, S. (2005). Dialogando com a Criatividade. São Paulo: Madras.

Estamatti, M. (2007). Programas em saúde mental comunitária. In A. Melillo \& E.N.S. Ojeda (Orgs.), Resiliência, descobrindo as próprias fortalezas (pp.151-160). Porto Alegre: Artmed.

Ferreira, M. P. (2008). Senhora das Imagens Internas- Escritos dispersos de Nise da Silveira. Coleção Cadernos da Biblioteca Nacional n.5. Rio de Janeiro: Fundação Biblioteca Nacional.

Frankl, V.E. (1987). Em busca de sentido: um psicólogo no campo de concentração. Porto Alegre: Sulina.

Frayze-Pereira J. A. (2003). Nise da Silveira: imagens do inconsciente entre psicologia, arte e política. Estudos Avançados, 17(49), 110.

Gardner, H. (1996). Mentes que criam. Porto Alegre: Artmed. 
Gardner, H. (2001). Inteligência - Um conceito reformulado. Rio de Janeiro: Objetiva.

Greco, C., Morelato, G., \& Ison, M. (2006). Emociones positivas: una herramienta psicológica para promocionarelproceso de resiliencia infantil. Psicodebate, (7), 81-94.

Gregerson, M.B.J. (2007). Creativity Enhances Practitioners' Resiliency and Effectiveness After a Hometown Disaster. Professional Psychology: Research and Practice, 38(6), 596602.

Guilford, J.P. (1967). The nature of human inteligence. New York: McGraw-Hill.

Han, M. (2010). How can creativity in a social context be possible? Culture \& Psychology, 16(2), 165-173.

Horta, B. C. (2008). Nise - Arqueóloga dos Mares. Brasil. Edições do Autor.

Infante, F. (2007). Resiliência como processo: uma revisão da literatura recente. In A. Melillo \& E.N.S. Ojeda (Orgs.), Resiliência, descobrindo as próprias fortalezas (pp. 23-38). Porto Alegre: Artmed.

Leal, L.G.P. (1994). Nise da Silveira - entrevista. Psicologia: ciência e profissão, 14(1-3), 22-27.

Lubart, T. (2007). Psicologia da Criatividade. Porto Alegre, Artmed.

Lubart, T. \& Guignard, J.H. (2004). The generality-specificity of creativity: a multivariate approach. In R.J. Sternberg, E.L. Grigorenko, \& J.L. Singer (Eds.), Creativity: from potential do realization (pp.43-56). Washington, DC: American Psychological Association.

Mallart, J. (2009). Ecoformação para a escola do século XXI. In M. Zwierewicz \& S. De La Torre (Orgs.), Uma escola para o século XXI - Escolas criativas e resiliência na educação (pp.29-41), Florianópolis: Insular.

Melillo, A. (2007). Resiliência e educação. In A. Melillo \& E.N.S. Ojeda (Orgs.), Resiliência, descobrindo as próprias fortalezas (pp.87101). Porto Alegre: Artmed.

Mello, W. (2001). Nise da Silveira- Pioneiros da Psicologia Brasileira. Rio de Janeiro: CRP/I mago, 2001.

Mesquita, L.R. (2000). Nise da Silveira e a luta por uma psiquiatria humanista e libertadora. Arquivos Brasileiros de Psicologia, 52(4), 59-66.

Morais, M.F. (2001). Definição e avaliação da criatividade: uma abordagem cognitiva. Braga: Universidade do Minho.

Munist, M., Santos, H., Kotliarenco, M. A., Ojeda. E. N. S., Infante, F., \& Grotberg, E. (1998). Manual de identificación y promoción de la resiliencia em ninõs y adolescentes. Washington: Organización Panamericana de Salud. 
Nakano, T. C. \& Wechsler, S. M. (2007). Criatividade: características da produção cientifica brasileira. Avaliação Psicológica, 6, 261270.

Ojeda, E.N.S. (2007). Uma concepção latino-americana: a resiliência comunitária. In A. Melillo \& E.N.S. Ojeda (Orgs.), Resiliência, descobrindo as próprias fortalezas (pp. 47-57). Porto Alegre: Artmed.

Oliveira, M.A., Reis, V.L., Zanelato, L.S., \& Neme, C.M.B. (2008). Resiliência: análise das publicações no período de 2000 a 2006. Psicologia ciência e profissão, 28(4), 754-767.

Oliveira, M.A. \& Nakano, T.C. (2011). Revisão de Pesquisa sobre Criatividade e Resiliência. Temas em Psicologia, 19(2), 467479.

Pinheiro, D. P. N. (2004). A resiliência em discussão. Psicologia em Estudo, 9(1), 67-75.

Reppold, C.T., Mayer, J.C., Almeida, L.S., \& Hutz, C.S. (2012). Avaliação da resiliência: controvérsia em torno do uso das escalas. Psicologia Reflexão e Crítica, 25(2), 248-255.

Rodriguez, D.H. (2007). O humor como indicador de resiliência. In A. Melillo \& E.N.S. Ojeda (Orgs.), Resiliência, descobrindo as próprias fortalezas (pp. 131-138). Porto Alegre: Artmed.

Romo, M. (2008). Creatividad em los domínios artístico y científico y sus correlatos educativos. In M.F. Morais \& B. Bahia (Coords.), Criatividade: Conceitos, Necessidades e Intervenção (pp. 6590). Braga: Psiquilibrios.

Sequeira, V.C. (2009). Resiliência e abrigos. Boletim -Academia Paulista de Psicologia, 29(1), 65-80.

Sternberg, R.J. (2000). Inteligência para o sucesso pessoal. Rio de Janeiro: Campus.

Taboada, N.G., Legal, E.J., \& Machado, N. (2006). Resiliência: em busca de um conceito. Rev. Brasileira de Crescimento e Desenvolvimento Humano, 16 (3), 104-113.

Torrance, E.P. (1966). Torrance tests of creative thinking. Lexington: Personnel Press.

Torrance, E.P., \& Ball, O.E. (1990). Streamlined Scoring and Interpretation Guide and Norms Manual Verbal and Figural Form B. Bensenville: Scholastic Testing Service.

Torrance, E.P., \& Safter, H.T. (1999). Making the creative leap beyond. Buffalo, NY: Creative Education Foundation.

Uicich, R. M. S. (2006) Superdotacíon y resiliencia. El cuerpo/sujeto resistente. In S. N. Freitas (Org.), Educação e altas habilidades/superdotação: a ousadia de rever conceitos e práticas ( pp. 245-256). Santa Maria: Ed UFSM.

Vignoli, T. (2000). Homenagem a uma guerreira da luz. Revista Kplus. Recuperado em 28 de outubro, 2011, de 
http://www. kplus.com. br/materia.asp?co=34\&rv=LiteraturaMan do

Wallach, M. A., \& Kogan, N. (1965). Modes of thinking in young children. New York: Holt, Rinehart\& Winston.

Wechsler, S. M. (2008). Criatividade: descobrindo e encorajando. Campinas: IDB.

Yunes, M. A. M. (2006). Psicologia positiva e resiliência: foco no indivíduo e na família. In: D.D. Dell Aglio, D. H. Koller \& M.A.M. Yunes (Orgs.). Resiliência e Psicologia Positiva:Interfaces do Risco à Proteção(pp. 69-81), São Paulo: Casa do Psicólogo.

\section{Endereço para correspondência}

Maria Antonia de Oliveira

Departamento de Pós-Graduação em Psicologia da PUC-Campinas

Avenida J ohn Boyd Dunlop, s/n, Jardim I paussurama, CEP 13060-904, Campinas SP, Brasil

Endereço eletrônico: poesiamaria@yahoo.com.br

\section{Tatiana de Cássia Nakano}

Departamento de Pós-Graduação em Psicologia da PUC-Campinas

Avenida J ohn Boyd Dunlop, s/n, Jardim I paussurama, CEP 13060-904, Campinas SP, Brasil

Endereço eletrônico: tatiananakano@puc-campinas.edu.br

Recebido em: 27/02/2012

Reformulado em: 21/01/2014

Aceito para publicação em: 02/02/2014

\section{Notas}

* Mestre em Psicologia pela Pontifícia Universidade Católica de Campinas, São José do Rio Preto, SP.

** Orientadora, Docente do curso de pós-graduação stricto sensu em Psicologia da PUC-Campinas, Campinas, SP. 